\title{
AVALIAÇÃO DA QUALIDADE DE CARDÁPIOS DA ALIMENTAÇÃO ESCOLAR NO ENSINO PÚBLICO
}

\author{
EVALUATION OF THE QUALITY OF SCHOOL FOOD MENU IN PUBLIC EDUCATION
}

Luiza Florentino dos Santos, Simone dos Anjos Caivano

Universidade Metropolitana de Santos

E-mail: luizaflorentino94@gmail.com

\begin{abstract}
RESUMO
Introdução: É na infância que se inicia a formação de hábitos, sobretudo os alimentares, e estimular o consumo de uma alimentação saudável viabiliza a educação alimentar e nutricional que se estende pela vida adulta. Os cardápios são importantes instrumentos para análise da qualidade das refeições através do Índice de Qualidade da Coordenação de Segurança Alimentar e Nutricional (IQ COSAN), que considera os componentes alimentares das refeições ofertadas para cada semana. Objetivo: Avaliar a qualidade dos cardápios da alimentação escolar oferecidos em escolas públicas da cidade de Santos/SP pelo Programa Nacional de Alimentação Escolar - PNAE. Casuística e métodos: Estudo original, de caráter transversal e qualitativo para análise de cardápios semanais, oferecidos em uma creche, uma Escola Municipal de Educação Infantil, (EMEI) e uma Escola Municipal de Ensino Fundamental (EMEF), conforme o IQ COSAN. Resultados: Embora os cardápios atendam às necessidades dos alunos, precisam de melhoras, de acordo com o IQ COSAN. Conclusão: Ampliar a diversidade alimentar e fazer uso controlado de alimentos restritos para alcançarem a classificação de "Adequado", pois diferentes faixas etárias necessitam de diferentes cardápios para melhorar o rendimento escolar e se desenvolvem como adultos de hábitos alimentares saudáveis.
\end{abstract}

Palavras-chave: Alimentação escolar; Cardápios; Hábitos; Educação alimentar.

\section{ABSTRACT}

It is in childhood that the formation of habits, especially eating habits, begins, and encouraging the consumption of healthy eating enables food and nutrition education that extends into adulthood. The menus are important instruments for analyzing the quality of meals through the Quality Index of the Food and Nutrition Security Coordination (IQ COSAN), which considers the food components of the meals offered each week. Objective: To evaluate the quality of school meals menus offered in public schools in the city of Santos/SP by the National School Food Program - PNAE. Material and methods: Original, transversal and qualitative study for the analysis of weekly menus, offered in a day care center, a Municipal School of Early Childhood Education (EMEI) and a Municipal Elementary School (EMEF), according to the IQ COSAN. Results: Although the menus meet the needs of students, they need improvement, according to the IQ COSAN. Conclusion: Expand food diversity and make controlled use of restricted foods to achieve the classification of "Adequate", as different age groups need different menus to improve school performance and develop as adults with healthy eating habits.

Keywords: School feeding; Menu; Nutrition Education. 


\section{V.10 N.1 (2022) ISSN: 2317-434X}

\section{INTRODUÇÃO}

A alimentação desempenha um papel fundamental no ciclo de vida de qualquer indivíduo. A idade escolar é uma fase decisiva para a formação de "hábitos alimentares, que tendem a continuar na vida adulta e por isso, a importância de estimular o consumo de uma alimentação variada e equilibrada" (BERNART, ZANARDO, 2011; ROSATO, STORCK, 2016). Assim sendo, depreende-se que a alimentação escolar é extremamente importante aos estudantes, uma vez que seu crescimento físico e mental se encontra em plena evolução nessa fase. A eles deve ser garantida uma alimentação de qualidade em atenção aos princípios da universalidade, equidade, sustentabilidade, continuidade, respeito aos hábitos alimentares dos escolares, descentralização e participação social (SANTOS; LEMOS; LAMOUNIER, 2010).

Para fomentar hábitos alimentares saudáveis nas escolas, o país criou em 1955 a Campanha da Merenda Escolar (BRASIL, 1955), passando a se chamar Programa Nacional de Alimentação Escolar (PNAE) com a lei $n^{\circ}$ 11.947/2009, que determina em seu artigo $4^{\circ}$ como objetivo:

[...] contribuir para o crescimento e o desenvolvimento biopsicossocial, a aprendizagem, o rendimento escolar e a formação de práticas alimentares saudáveis dos alunos, por meio de ações de educação alimentar e nutricionais e da oferta de refeições que cubram as suas necessidades nutricionais durante $\mathrm{o}$ período letivo (BRASIL, 2009).

Criado na década de 1950, o Programa Nacional de Alimentação Escolar (PNAE), é considerado "uma das políticas públicas mais antigas do país e um dos maiores programas de alimentação escolar do mundo" (GOMES; FANHANI, 2014). Estabelecido como política governamental em esfera nacional, o PNAE visa suprir uma parcela mínima (em torno de 15\%) das necessidades alimentares ou nutricionais dos alunos enquanto permanecessem na escola (TOLEDO et al., 2012). Para TOLEDO e DECKER o governo cumpre um importante papel social no país e reconhece a alimentação como um direito dos alunos da rede pública, garantindo o atendimento universal, determinado pela Constituição Federal (TOLEDO et al., 2012; DECKER, STRACK, GIOVANONI, 2013).

Como eixo das políticas públicas da segurança alimentar e nutricional dos alunos em idade de crescimento e desenvolvimento de suas capacidades motoras e cognitivas, o PNAE promove uma alimentação saudável com o acesso a alimentos básicos in natura e redução da oferta de alimentos industrializados, fortalecendo a produção agrícola, direcionada para a agricultura familiar, que repercute em inclusão social e no desenvolvimento local ou regional, quando potencializa a produção e comercialização dos recursos e produtos locais (MOSSAMANN; TEO, 2017).

O Fundo Nacional de Desenvolvimento da Educação (FNDE) também determina no artigo 13 da Resolução do Conselho Diretivo $\mathrm{n}^{\circ}$ 26, de 17 de junho de 2013, que além dos objetivos do PNAE, sejam implementados um "conjunto de ações formativas que objetivam estimular a adoção voluntária de práticas e escolhas alimentares saudáveis, que colaborem para a aprendizagem, o estado de saúde do escolar e a qualidade de vida do indivíduo" (PNAE; 2009). Os agravantes ao seu desenvolvimento provocados pela nutrição empobrecida podem comportar características como: baixo crescimento, evolução deficiente ou anormal de órgãos, baixo desempenho cognitivo, falhas adaptativas, problemas psicológicos e de socialização, entre outras (DECKER; STRACK; GIOVANONI, 2013).

Ao buscar atender às necessidades nutricionais das crianças por meio de um cardápio alimentar balanceado, o PNAE também inclui incentivos ao desenvolvimento agrícola local ou regional conforme a Resolução/CD/FNDE no 38, de 16 de julho de 2009 (BRASIL, 2009). É amplamente reconhecido que para a implementação do plano, é importante "considerar alguns pré-requisitos, tais como: fornecer refeições nutritivas, implementar ações de EAN, respeitar a cultura local, participação social e promover famílias agrícolas" para ajudar a melhorar A eficácia do PNSAN (Política de Segurança Alimentar e Nutricional) (ROCHA et al. 2018).

O artigo 14 da Lei ${ }^{\circ} 11.947$ estipula que parte dos recursos $(30 \%)$ do FNDE deve ser destinada à compra de produtos agrícolas, preferencialmente produzidos por grupos vinculados à agricultura familiar, comunidades indígenas e quilombolas. (BRASIL, 2009)

A aquisição de alimentos in natura requer diretamente a participação da produção agrícola, priorizando a agricultura familiar que se sente fortalecida pelo Programa. Dessa forma, o PNAE, ao permitir a comercialização desses produtos, assume caráter de política pública estruturante, que repercute no desenvolvimento local ou regional. Nessa perspectiva, o programa de alimentação escolar aparece como potencial reintegrador da agricultura familiar para o enfrentamento do problema de produção e consumo de alimentos. Ao mesmo tempo, contribui para a integração de políticas relacionadas à saúde de escolares e a criação de mercados 


\section{V.10 N.1 (2022) ISSN: 2317-434X}

para os agricultores familiares (TRICHES RM; SCHNEIDER S, 2010).

A Resolução n 465/2010 identificou 13 tarefas obrigatórias, as quais devem ser compostas por nutricionistas reconhecidos como RTs de alimentação escolar no município e / ou entidade executiva e uma equipe técnica composta por outros nutricionistas que atuam na execução de Pessoal da área de alimentação escolar. A resolução também orienta as autoridades municipais de um número adequado de nutricionistas com base no número de alunos matriculados em escolas públicas. (BRASIL, 2010)

Segundo SANTOS (SANTOS; LEMOS; LAMOUNIER, 2010) uma dieta alimentar adequada, particularmente na fase de crescimento e maturação do corpo, possibilita minimizar possíveis riscos à saúde e ao desenvolvimento normal, além de produzir melhoras na aprendizagem ou reduzir o baixo desempenho escolar. Para GOMES \& FANHANI (GOMES; FANHANI, 2014) a aquisição de hábitos alimentares saudáveis deve ser estimulada devido à longa permanência desses indivíduos no ambiente escolar.

Dessa forma, conforme a Resolução $\mathrm{CD} \mathrm{n}^{\circ}$ 26, deve-se atentar ao atendimento às necessidades e exigências nutricionais da clientela escolar, específicas ao seu grau de maturação e desenvolvimento, uma vez que os hábitos alimentares repercutem nas condições de saúde na idade adulta e, portanto, sua formação nesse grupo etário merece maior atenção quanto à oferta de produtos em quantidade e de qualidade, com uma dieta balanceada, suficiente para satisfazer suas necessidades nutricionais mínimas de atendimento e obediência às diretrizes propostas pelo PNAE (FNDE, 2013).

A Lei $\mathrm{n}^{\circ} 11.947$ reafirma e reforça essa função básica do nutricionista. Respeitar as diretrizes previstas para o plano, é obrigatório, de acordo com o art. 11. Responsabilidade técnica pela alimentação escolar, e com base no art. 12. Utilizar ingredientes básicos na elaboração dos cardápios, obedecer às "referências nutricionais locais, hábitos alimentares, cultura e tradições alimentares", e priorizar a "sustentabilidade e diversificação agrícola na região, alimentação saudável e adequada" (BRASIL,2009).

Vale mencionar, a Resolução $\mathrm{n}^{\circ} 06$ de 08 de maio de 2020 (FNDE, 2020) do FNDE que entrará em vigor em janeiro/2021, invalidando, as Resoluções CD n²6 de 17 de junho de 2013, $n^{\circ} 04 / 2015, n^{\circ} 01 / 2017$ e $n^{\circ} 18 / 2018$, que estabelece sobre o atendimento da alimentação escolar aos alunos da educação básica, no contexto do PNAE.

As formas de gestão das escolas do PNAE e da Prefeitura Municipal de Santos seguem um modelo centralizado. De acordo com o artigo $8^{\circ}$ da Resolução ${ }^{\circ}$
6/2020, na gestão centralizada, a entidade executiva (prefeitura) obtém alimentos, que são fornecidos às unidades escolares para o preparo e distribuição da merenda escolar. Os fornecedores podem entregar alimentos diretamente nas unidades escolares e pode haver um depósito central como intermediário de abastecimento.

Sendo assim, os cardápios devem oferecer "alimentos variados, seguros, que respeitem a cultura, tradições e hábitos alimentares saudáveis” (FNDE, 2013). Para VASCONCELOS e PNAE (VASCONCELOS et al., 2012; BRASIL 2009) os critérios padrões para a elaboração de cardápio de qualidade abrangem:

a) frutas variadas de acordo com a safra, o mínimo de três porções por semana;

b) verduras diversas, isoladamente ou combinadas entre si, o mínimo de três porções por semana;

c) alimentos de origem animal ricos em ferro (carnes, miúdos e fígado);

d) preparações com pouca quantidade de gordura (assados, cozidos, ensopados, grelhados);

e) controle de guloseimas, açúcar, alimentos processados, frituras e bebidas de baixo valor nutricional.

$\mathrm{O}$ valor nutricional mínimo definido pelo PNAE para a alimentação escolar brasileira equivale a, pelo menos, $15 \%$ das necessidades individuais diárias dos principais nutrientes. Os alimentos que compõem os cardápios da alimentação escolar devem atender às necessidades nutritivas dos usuários do PNAE (BRASIL, 2009) e considerar as recomendações e sugestões das Referências Nutricionais do PNAE (VASCONCELOS et al., 2012). A sua qualidade pode ser avaliada pelo IQ COSAN, que padroniza as análises e pontua os componentes alimentares das refeições ofertadas para cada semana, e se "atendem às diretrizes do PNAE e aos pilares de uma alimentação adequada e saudável" (PNAE, 2018). O IQCOSAN foi criado e aperfeiçoado pela Coordenação Alimentar e Nutricional (CONSAN), para padronizar as análises dos cardápios feitas por técnicos do FNDE e por nutricionistas e demais profissionais que atuam no PNAE, "que desejam verificar se os cardápios elaborados atendem às diretrizes do Programa e aos pilares de uma alimentação adequada e saudável" (PNAE, 2018).

\section{MÉTODO}

Desenho do estudo. Este estudo foi aprovado pela Secretaria de Educação, ofício no 1591 de 29 de agosto de 2019, de delineamento descritivo e qualitativo, a partir da avaliação dos cardápios semanais oferecidos para alunos matriculados em uma creche, uma Escola Municipal de 


\section{V.10 N.1 (2022) ISSN: 2317-434X}

Educação Infantil, (EMEI) e uma Escola Municipal de Ensino Fundamental (EMEF) da cidade de Santos/SP, de acordo com as exigências alimentares e nutricionais propostas pelo PNAE.

Coleta de dados. O índice utilizado foi Índice de Qualidade da Coordenação de Segurança Alimentar e Nutricional (IQ COSAN), que considera os componentes alimentares das refeições ofertadas para cada semana, analisados durante o período de 03 junho à 28 de junho, para cinco níveis de ensino diferentes (Creches, EMEF parcial manhã, EMEF parcial tarde, EMEF período integral, EMEI educação infantil), os detalhes sobre o índice estão disponíveis no site do FNDE (PNAE, 2018).

Análise de dados. O índice utilizado foi Índice de Qualidade da Coordenação de Segurança Alimentar e Nutricional (IQ COSAN), que considera os componentes alimentares das refeições ofertadas para cada semana, analisados durante o período de 03 junho à 28 de junho, para cinco níveis de ensino diferentes (Creches, EMEF parcial manhã, EMEF parcial tarde, EMEF período integral, EMEI educação infantil), os detalhes sobre o índice estão disponíveis no site do FNDE (PNAE, 2018).

Cada cardápio é pontuado pela composição semanal, sem indicativo dos dias da semana e independentemente da quantidade de vezes que o alimento é ofertado, isto é, os pontos são mantidos mesmo que o alimento esteja presente em mais de um dia da semana. A somatória dos pontos indica a classificação final dos cardápios da seguinte forma: Inadequado ( 0 a 45,9 pontos); necessita de melhorias (46 a 75,9 pontos) e adequado (76 a 95 pontos).

\section{RESULTADOS}

Para todas as modalidades de ensino, a oferta de muitos alimentos da sociobiodiversidade foi pontuada nos itens "alimentos regionais" e "alimentos da sociobiodiversidade", pois se refere ao alimento típico ofertado da região analisada, de acordo com o manual "Alimentos regionais brasileiros" do Ministério da Saúde (BRASIL, 2015). Para a cidade de Santos/São Paulo, localizada na Região Sudeste, os alimentos e preparações regionais são:

Frutas: abacate, brejaúva (coco-brejáuva, airi, brejaúba), caqui, carambola, goiaba, jabuticaba, jaca, jambolão (jamelão, jalão, azeitona-do-nordeste, cereja, ameixa-roxa, jambuí, guapê), laranja, pinha (ata, fruta-doconde), sapucaia (castanha-sapucaia, cumbuca-demacaco) e sapoti (sapotinha).

Hortaliças: abobrinha (abobrinha, abóbora-demoita, abobrinha italiana e abobrinha verde), agrião (agrião-d'água), berinjela, beldroega (beldroega, bredo, salada-de-negro, berdolaca, verdoloca eberduega), capiçoba (gondó, maria-gondó, maria-gomes e capiçova), capuchinha (capuchinha, chaguinha, chagas, papagaios, flor-de-sangue, agrião-do-méxico, flor-de-chagas, esporade-galo, agrião-grande-do-peru), couve (couve-manteiga e couve-de-folhas), espinafre, jiló, mostarde-de-folha (mostarda, mostarda ardida), ora-pró-nóbis (groselheiradas-antilhas, lobrobó, groselha-da-américa e groselheirade-barbados), quiabo, repolho, rúcula (pinchão), taioba (taia) e vagem (feijão-vagem).

Leguminosas: feijão branco, grão-de-bico, orelha-de-padre (orelha-de-padre, lab lab, mangalôamargo).

Preparações especiais: mandioquinha-salsa (mandioquinha-salsa, mandioquinha, baroa, batata baroa, fiuza, cenoura-amarela, batata-aipo), milho espiga e taro (inhame, cará).

Abaixo estão apresentadas as informações sobre a qualidade dos cardápios conforme as modalidades de ensino analisadas. Na Tabela constam as informações detalhadas sobre a pontuação de acordo com o IQ COSAN (PNAE, 2018).

\section{Creches}

Conforme o relatório nutricional do PNAE (VASCONCELOS et al., 2012), os cardápios para as crianças de 1 a 30 meses de idade, estudando em meio período, devem cobrir o mínimo de $70 \%$ das Necessidades Nutricionais Diárias (NND). Os itens mais importantes são o leite, papinhas de frutas e sopas de legumes variados, iniciando-se a formação dos hábitos alimentares, como outro viés na preocupação do PNAE e que está na base do Programa (ROCHA et al., 2018).

Os cardápios avaliados ofertaram desjejum, almoço e lanche, contendo nele, leite enriquecido com achocolatados, verduras e legumes, arroz e feijão, macarrão, feculento de batata com salsa, purê de leguminosa, frutas (não especificadas) e proteínas. Houve baixa oferta de alimentos diversificados e alta oferta de alimentos restritos ou doces (> 2 vezes na semana).

A baixa oferta de alimentos diversificados e alta oferta de alimentos restritos ou doces ( $>2$ vezes na semana) determinou a pontuação final de 75,67 pontos, classificado como "Precisa de melhoras" (Tabela).

\section{EMEF parcial manhã}

O cardápio para a faixa etária de 6 a 10 anos, matriculadas no ensino fundamental, em meio período parcial (manhã), deve atender a $20 \%$ das Necessidades Nutricionais Diárias (NND) (VASCONCELOS et al., 


\section{V.10 N.1 (2022) ISSN: 2317-434X}

2012).

Nos cardápios avaliados contendo lanche e almoço, houve baixa oferta de alimentos diversificados, presença de alimentos proibitivos e baixa oferta de frutas e hortaliças ( $<2$ vezes na semana), na semana 3 .

No desjejum são ofertados leite com achocolatado, bisnaguinha, biscoito doce e no almoço, salada de verdura; arroz com feijão; alimentos proteicos pertencentes ao sexto grupo dos alimentos, como carnes, aves, pescados e ovos; proteína com legumes; macarrão com molho e frutas. Entretanto, há presença de alimentos considerados restritos, de acordo com o IQ COSAN (PNAE, 2018).

Com a presença de 20 componentes nas semanas 1 e 2 e 27 na semana 3, o total final foi de 63,67 pontos, classificação "Precisa de melhoras" devido à baixa oferta de alimentos diversificados, a presença de alimentos proibitivos e a baixa oferta de frutas e hortaliças $(<2$ vezes na semana), na semana 3 (Tabela).

\section{EMEF parcial tarde}

A referência de Necessidades Nutricionais Diárias (NND) para crianças de 11 a 15 anos, matriculadas no ensino fundamental, em meio período parcial (tarde), é de $20 \%$ (VASCONCELOS et al., 2012).

Cardápios avaliados contendo em si almoço e lanche, no almoço é servido salada de verdura, arroz com feijão, proteína e proteína com legumes, frutas e no lanche da tarde, leite com achocolatado, bisnaguinha, pão com enriquecedor (não discriminado), biscoito e bolinho individual. Entretanto, houve a oferta de alimentos considerados altamente restritos e baixa oferta de frutas e hortaliças ( $<2$ vezes por semana), na semana 3 .

Entretanto, com a ofertas de alimentos considerados altamente restritos e baixa oferta de frutas e hortaliças $(<2$ vezes por semana), na semana 3 , somou 61,67 pontos e classificado como "Precisa de melhoras" (Tabela).

\section{EMEF período integral}

O cardápio deve cobrir $70 \%$ das NDD (VASCONCELOS et al., 2012) das crianças de 6 a 10 anos, matriculadas no ensino fundamental, em período integral.
Cardápios compostos por refeições diárias possuindo desjejum, almoço, lanche e jantar. Sendo que, no almoço e lanche houve baixa diversidade de alimentos e falta de alimentos ricos em proteínas, pertencentes ao grupo "carnes e ovos", como por exemplo carnes, aves, pescados e ovos e houve a presença de alimentos considerados restritos.

Composto por 2 refeições diárias e lanche da tarde, mostra a presença de 23 componentes alimentares nas semanas 1 e 3, e 25 na semana 2. Com isso, fica comprovado sua baixa diversidade que, aliado à falta de alimentos ricos em proteínas, pertencentes ao sexto grupo dos alimentos, como carnes, aves, pescados e ovos e a presença de alimentos considerados restritos, obtém o total de 58,67 pontos, classificado como "Precisa de melhoras" (Tabela).

\section{EMEI educação infantil}

A cobertura dos $30 \%$ das NND\% (VASCONCELOS et al., 2012), é recomendada aos alunos que possuem entre 6 e 10 anos, matriculados em meio período, servindo desjejum, almoço e lanche.

No desjejum consta a presença dos produtos como leite com achocolatado, pão com enriquecido, bisnaguinha, biscoito, bolinho individual. No almoço, salada de verdura, arroz com feijão, proteína e proteína com legumes, feculento e proteína com feculento, frutas. Empregam-se aqui, também, produtos para a alimentação diária em período integral. Arroz, pão com enriquecedor, legumes e hortaliças são os principais responsáveis pelo fornecimento de energia, junto com os carboidratos, como cereais (arroz), leguminosas (feijão) e biscoito. A eles, soma-se a complementação alimentar com proteínas e fonte de minerais (leite, legumes e frutas ou suco de frutas). As fibras alimentares estão representadas pelo feijão, cereais e tubérculos (arroz, pão com enriquecedor, biscoito); as fontes de vitaminas, pelo leite, verduras e frutas.

Com 30 componentes alimentares na semana 1,35 na 2 e 31 na semana 3 , além de alimentos proteicos do grupo 6 dos alimentos, como carnes, aves, pescados e ovos, e atingiu 73,67 pontos e classificado como "Precisa de melhoras" pela oferta baixa na diversidade de alimentos e presença de alimentos considerados restritos (Tabela). 


\section{V.10 N.1 (2022) ISSN: 2317-434X}

Tabela - Pontuação e média dos componentes de análise do Índice de Qualidade da Coordenação Alimentar Nacional (IQ COSAN) das semanas analisadas dos cardápios da alimentação escolar das escolas públicas da cidade de Santos. Brasil, 2021.

\begin{tabular}{|c|c|c|c|c|c|c|c|c|c|c|c|c|c|c|c|}
\hline \multirow{2}{*}{ Semana } & \multicolumn{11}{|c|}{ Grupo de alimentos } & \multirow[t]{2}{*}{ TC } & \multirow[t]{2}{*}{ PT } & \multirow[t]{2}{*}{ Média } & \multirow[t]{2}{*}{ Classificação } \\
\hline & CT & $\mathbf{F e}$ & $\mathbf{L V}$ & $\mathbf{F r}$ & LD & $\mathrm{CO}$ & $\overline{\mathbf{A R}}$ & PD & $\mathbf{A P}$ & $\mathbf{A R}$ & $\mathbf{A S}$ & & & & \\
\hline \multicolumn{16}{|l|}{ Creches } \\
\hline 1 & 10 & 10 & 10 & 10 & 10 & 10 & 0 & 0 & 0 & 2,5 & 2,5 & 31 & 75 & \multirow{3}{*}{75,67} & \multirow{3}{*}{$\begin{array}{l}\text { Precisa de } \\
\text { melhoras }\end{array}$} \\
\hline 2 & 10 & 10 & 10 & 10 & 10 & 10 & 0 & 2 & 0 & 2,5 & 2,5 & 34 & 77 & & \\
\hline 3 & 10 & 10 & 10 & 10 & 10 & 10 & 0 & 0 & 0 & 2,5 & 2,5 & 30 & 75 & & \\
\hline \multicolumn{16}{|c|}{ EMEF parcial manhã } \\
\hline 1 & 8 & 8 & 10 & 8 & 10 & 10 & 0 & 0 & 0 & 2,5 & 2,5 & 20 & 60 & \multirow{3}{*}{63,67} & \multirow{3}{*}{$\begin{array}{c}\text { Precisa de } \\
\text { melhoras }\end{array}$} \\
\hline 2 & 10 & 10 & 8 & 6 & 4 & 10 & 0 & 0 & 0 & 2,5 & 2,5 & 20 & 69 & & \\
\hline 3 & 10 & 8 & 10 & 4 & 10 & 10 & 0 & 0 & 0 & 2,5 & 2,5 & 27 & 62 & & \\
\hline \multicolumn{16}{|c|}{ EMEF parcial tarde } \\
\hline 1 & 8 & 8 & 8 & 6 & 10 & 10 & 0 & 0 & 0 & 2,5 & 2,5 & 20 & 60 & \multirow{3}{*}{61,67} & \multirow{3}{*}{$\begin{array}{l}\text { Precisa de } \\
\text { melhoras }\end{array}$} \\
\hline 2 & 8 & 6 & 10 & 4 & 10 & 10 & 0 & 0 & 0 & 2,5 & 2,5 & 22 & 63 & & \\
\hline 3 & 10 & 8 & 10 & 4 & 10 & 10 & 0 & 0 & 0 & 2,5 & 2,5 & 18 & 62 & & \\
\hline \multicolumn{16}{|c|}{ EMEF integral } \\
\hline 1 & 10 & 6 & 8 & 6 & 10 & 10 & 0 & 0 & 0 & 2,5 & 2,5 & 23 & 62 & \multirow{3}{*}{58,67} & \multirow{3}{*}{$\begin{array}{c}\text { Precisa de } \\
\text { melhoras }\end{array}$} \\
\hline 2 & 10 & 8 & 10 & 4 & 10 & 10 & 0 & 0 & 0 & 2,5 & 2,5 & 25 & 67 & & \\
\hline 3 & 10 & 8 & 10 & 4 & 10 & 10 & 0 & 0 & 0 & 2,5 & 2,5 & 23 & 62 & & \\
\hline \multicolumn{16}{|c|}{ EMEI educação infantil } \\
\hline 1 & 8 & 8 & 10 & 10 & 10 & 10 & 0 & 0 & 0 & 2,5 & 2,5 & 30 & 71 & \multirow{3}{*}{73,67} & \multirow{3}{*}{$\begin{array}{l}\text { Precisa de } \\
\text { melhoras }\end{array}$} \\
\hline 2 & 10 & 10 & 10 & 10 & 10 & 10 & 0 & 0 & 0 & 2,5 & 2,5 & 35 & 75 & & \\
\hline 3 & 10 & 10 & 10 & 10 & 10 & 10 & 0 & 0 & 0 & 2,5 & 2,5 & 31 & 75 & & \\
\hline
\end{tabular}

CT: Cereais e Tubérculos; Fe: Feijões; LV: Legumes e Verduras; Fr: Frutas in natura; LD: Leite e Derivados; CO: Carnes e Ovos; AR: Alimentos Restritos; PD: Preparações Doces; AP: Alimentos Proibidos; AR: Alimentos Regionais; AS: Alimentos da Sociobiodiversidade; TC: Total de Componentes; PT: Pontuação Total; EMEF: Escola Municipal de Ensino Fundamental;EMEI: Escola Municipal de Educação Infantil.

\section{DISCUSSÃO}

Acredita-se que um dos fatores na construção de um contexto nutricional negativo sejam alterações nos hábitos alimentares e do estilo de vida da população. Ademais, a inversão do estado nutricional dos brasileiros, passando da desnutrição ou nutrição deficiente para a obesidade e sobrepeso, já estão presentes em crianças na idade escolar e adolescentes (COSTA et al., 2016), e a obesidade e o sobrepeso tendem a desenvolver estados precoces de várias doenças como as doenças cardiovasculares, diabetes mellitus, e problemas psicológicos e de socialização.

O resultado dos hábitos alimentares não compatíveis com uma alimentação saudável da população brasileira, nas últimas três décadas, são os índices preocupantes "de comportamento epidemiológico em relação à problemática do sobrepeso e obesidade, ao mesmo tempo em que apresenta declínio relevante da desnutrição em crianças e adultos" (COSTA et al., 2016).

Essa tendência de aumento de sobrepeso e de obesidade em crianças e adolescentes, independente do grau de desenvolvimento econômico, traz ainda alterações no consumo alimentar, hábitos alimentares inadequados vinculados a um maior consumo de alimentos industrializados, ricos em açúcares e sódio, e a dietas contendo maior densidade energética - o que marca uma transição de hábitos nutricionais no país (TIRP et al., 2014; COSTA et al., 2016) relatam estatísticas do ano de 2009 , segundo as quais "uma em cada três crianças de 5 a 9 anos estavam acima do peso recomendado pela Organização Mundial de Saúde". Ainda segundo suas 


\section{V.10 N.1 (2022) ISSN: 2317-434X}

pesquisas, o "número de crianças acima do peso mais que dobrou entre 1989 e 2009 , passando de $15 \%$ para $34,8 \%$. $\mathrm{O}$ número de obesos aumentou mais de $300 \%$ nesse mesmo grupo etário, indo de 4,1\% em 1989 para 16,6\% em 2008-2009" (COSTA et al., 2016).

Também é preocupante o baixo consumo de frutas e hortaliças, essenciais para uma dieta saudável e na prevenção de doenças crônicas não transmissíveis, como sobrepeso e obesidade (TIRP et al., 2014). A alimentação inadequada, com reduzido consumo desses alimentos, é responsável, anualmente, por cerca de 2,7 milhões de mortes relacionadas a essas doenças (VASCONCELOS et al., 2012).

A formação de hábitos alimentares, como viés na preocupação do PNAE e que está na base do Programa (ROCHA et al., 2018) a partir da infância e influenciada pela cultura local e diretamente pela ingestão habitual de alimentos repercute nas condições de saúde na idade adulta. Logo, a alimentação escolar deve ser de qualidade e quantidade adequadas aos alunos de cada escola: para atender ao mínimo das necessidades nutricionais; possibilitar melhor desenvolvimento cognitivo, motor e físico, com possível prevenção de doenças, melhor assimilação de conhecimentos e, em consequência, melhor aprendizagem; e redundar, finalmente, na aquisição de hábitos alimentares saudáveis (BERNART, ZANARDO, 2011; ROSATO, STORCK, 2016; COSTA et al., 2016).

Daí a importância de fornecer alimentos em quantidade e qualidade em uma dieta balanceada, o que pode minimizar riscos à saúde e permitir um desenvolvimento e crescimento satisfatório, principalmente devido ao longo período de permanência das crianças na escola (GOMES; FANHANI, 2014).

É fundamental que as crianças desde cedo, tanto em casa como no ambiente escolar, construam hábitos alimentares saudáveis, podendo espelhar-se no exemplo que a alimentação escolar oferece quanto a refeições equilibradas e de qualidade, com produtos naturais e de alto valor nutricional - o que favorece, igualmente, a educação alimentar. Nesse sentido, o FNDE, por meio de suas recomendações, busca promover a educação alimentar e nutricional, que tem como uma das estratégia a oferta da alimentação saudável na escola (BRASIL, 2009).

É imprescindível destacar a importância do PNAE como um dos maiores programas de alimentação escolar do mundo, com cobertura de mais de $20 \%$ da população brasileira, que contribui para a formação de hábitos saudáveis de alimentação, desde a infância, e para a inclusão social, incentivando e fomentando a agricultura familiar e regional.

Diferenciar os cardápios por faixa etária, com diversidade de alimentos e com respeito à cultura e às tradições contribui, segundo o artigo $2^{\circ}$ da Resolução $n^{\circ}$ 26 "para o crescimento e o desenvolvimento dos alunos e para a melhoria do rendimento escolar" (PNAE, 2009).

\section{CONCLUSÃO}

Este é um estudo inédito uma vez que a busca por publicações que utilizaram os critérios IQ COSAN para analisar a qualidade da alimentação escolar, resultou em apenas dois trabalhos com avaliações específicas sobre alimentação regional - fruta nativa (QUINALHA, 2019) e preparações com produtos regionais (GUIMARÃES et al., 2019). no ambiente escolar.

Sobre os cardápios avaliados é possível afirmar que atende aos parâmetros propostos para cada faixa etária, mas classificados como "Precisa de melhoras", indicando haver espaço para evolução, para que os cardápios sejam mais saudáveis e atinjam, mais rapidamente, a categoria máxima.

Com a baixa diversidade de alimentos e a presença de alimentos considerados proibidos ou restritos (achocolatados) em todos eles, cabe à Prefeitura de Santos ampliar a diversidade alimentar e reduzir a oferta dos alimentos proibidos ou restritos, para aumentar os hábitos saudáveis de alimentação e cumprir mais fielmente as especificações do FNDE. Além disso, deveria também viabilizar os produtos regionais, contribuindo para a valorização da agricultura local e microempreendedores com o fornecimento e enriquecimento da alimentação escolar em forma de licitações, inclusive para atender muitos escolares das regiões indígenas e quilombolas, que ao vir morar na cidade acabam sentindo falta de muitos alimentos e essa demanda poderá ser minimizada. 


\section{REFERÊNCIAS}

BERNART, A.; ZANARDO, V. P. S. Educação nutricional para crianças em escolas públicas de Erechim/RS. Rev. Elet. Extensão da URI., 7(13): 71-79, 2011.

BRASIL. Decreto $\mathrm{n}^{\circ}$ 37.106, de 31 de março de 1955. Institui a Campanha da Merenda Escolar. Diário Oficial da União, Seção 1, de 2 abr. 1955. Brasília, DF, Presidência da República, 1955.

BRASIL. Lei $\mathrm{n}^{\circ}$ 11.947, de 16 de junho de 2009. Conversão da Medida Provisória ${ }^{\circ} 455$, de 2008. Dispõe sobre $o$ atendimento da alimentação escolar e do Programa Dinheiro Direto na Escola aos alunos da educação básica [...]; e dá outras providências. Diário Oficial da União, de 17 jun. 2009. Brasília, DF, Presidência da República, 2009.

BRASIL. Ministério da Saúde. Secretaria de Atenção à Saúde. Departamento de Atenção Básica. Alimentos regionais brasileiros 2. ed. - Brasília: Ministério da Saúde, 2015.

BRASIL. Resolução/CD/FNDE $n^{\circ}$ 38, de 16 de julho de 2009. Dispõe sobre o atendimento da alimentação escolar aos alunos da educação básica no Programa Nacional de Alimentação Escolar - PNAE. Diário Oficial da União 17 jul. 2009.

BRASIL. Resolução CFN n ${ }^{\circ}$ 465/2010, de 23 de agosto de 2010. Dispõe sobre as atribuições do Nutricionista, estabelece parâmetros numéricos mínimos de referência no âmbito do Programa de Alimentação Escolar (PAE) e dá outras providências. Diário Oficial da União. Brasília, DF, 23 ago. 2010. Disponível em:

https://www.cfn.org.br/wpcontent/uploads/resolucoes/Re s_465_2010.htm. Acesso em 17 set. 2021.

BRASIL. Resolução n ${ }^{\circ}$ 06, de 08 de maio de 2020. Dispõe sobre o atendimento da alimentação escolar aos alunos da educação básica no âmbito

do Programa Nacional de Alimentação Escolar - PNAE. Diário Oficial da União. Brasília, DF, 08 mai. 2020. Disponível em: https://www.in.gov.br/en/web/dou//resolucao-n-6-de-8-de-maio-de-2020-256309972.

Acesso em 17 set. 2021.
COSTA et al. Avaliação da composição nutricional dos cardápios da alimentação escolar das escolas da rede municipal de tempo integral do Município de Fortaleza, CE. In: Revista DigitalEFDeportes.com, Buenos Aires, Enero 2016; año 20(212). Disponível em: <Disponível em: https://www.efdeportes.com/efd212/composicaonutricional-dos-cardapios-das-escolas.htm>. Acesso em 23 fev. 2019.

DECKER, M.; STRACK, M.H.; GIOVANONI, A.B. Avaliação da alimentação escolar oferecida aos alunos do ensino fundamental das escolas municipais em um município do Vale do Taquari-RS. In: Revista Destaques Acadêmicos, CCBS/UNIVATES, 2013; 5(3) p. 13-18.

FNDE - Fundo Nacional de Desenvolvimento da Educação. Resolução/CD/FNDE nº 26, de 17 de junho de 2013. Dispõe sobre o atendimento da alimentação escolar aos alunos da educação básica no âmbito do Programa Nacional de Alimentação Escolar - PNAE. Ministério da Educação; 2013. 44p.

FNDE - Fundo Nacional de Desenvolvimento da Educação. Resolução/CD/FNDE $n^{\circ}$ 06, de 08 de maio de 2020. Dispõe sobre o atendimento da alimentação escolar aos alunos da educação básica no âmbito do Programa Nacional de Alimentação Escolar - PNAE. Ministério da Educação; 2020. 35p

GOMES, C.; FANHANI, A.P. Avaliação da qualidade nutritiva do cardápio da alimentação escolar de Luiziana, PR. In: SaBios: Rev. Saúde e Biol., out./dez; 2014; 9(3): 53-61. ISSN: 1980-0002.

GUIMARÃES, et al. Regionalismo presente nos cardápios da alimentação escolar no município de Campinorte Goiás. 2019. Disponível em: <Disponível em: http://www.seer.ufu.br/index.php/hygeia/article/view/470 97>. Acesso em 03 ago. 2019.

Ministério da Educação. FNDE- Fundo Nacional do Desenvolvimento da Educação. Conselho Deliberativo. (Brasil). Resolução n 26, de 17 de julho de 2013. Dispõe sobre o atendimento de alimentação escolar aos alunos da educação básica no âmbito do Programa Nacional da Alimentação Escolar- PNAE. Ministério da Educação; 
MOSSMANN, M.P.; TEO, C.R.P.A. Alimentos da agricultura familiar na alimentação escolar: percepções dos atores sociais sobre a legislação e sua implementação. In: Interações, Campo Grande, MS, abr./jun. 2017; 18(2): 31-43.

PNAE - Programa Nacional de Alimentação Escolar. Índice de Qualidade IQCOSAN: Manual. FNDE: PNAE; 2018.

QUINALHA LF. Adesão e aceitabilidade de cucas com ananás bracteatus por escolares do município de Morrinhos do Sul-RS. 2019. Disponível em: <Disponível em: https://www.lume.ufrgs.br/handle/10183/198963>. Acesso em 03 ago. 2019. Referências nutricionais para o Programa Nacional de Alimentação Escolar (PNAE). Documento final referente ao Grupo de Trabalho, revisado pelo Centro de Referência. FNDE; jun. 2009. 45p.

ROCHA et al. Análise do programa nacional de alimentação escolar no município de Viçosa, MG, Brasil. In: Rev Saúde Public., 2018; (52):16-25.

ROSSATO, B.M.; STORCK C.R. Adequação nutricional da alimentação escolar oferecido em instituições de ensino da rede estadual. In: Disciplinarum Scientia, série Ciências da Saúde, Santa Maria/RS, 2016; 17(1): 73-82.

SANTOS, J.N.; LEMOS, S.M.A.; LAMOUNIER, J.A. Estado nutricional e desenvolvimento da linguagem em crianças de uma creche pública. In: Rev Soc Bras Fonoaudiol. 2010; 15(4): 566-71.

TIRP et al. Comparação entre o consumo alimentar de estudantes e o preconizado do programa nacional de alimentação escolar. In: Revista Uningá, out.-dez. 2014; 42: 32-38.

TOLEDO et al. Avaliação e comparação do cumprimento dos cardápios da merenda escolar em uma escola da rede pública municipal de ensino. In: Revista Ciências em Saúde, out. 2012; 2(4); 8 p.

TRICHES RM, SCHNEIDER S. Alimentação escolar e agricultura familiar: reconectando o consumo à produção. Saúde Soc. 2010; 19(4): 933-945.

VASCONCELOS et al. Manual de orientação para a alimentação escolar na educação infantil, ensino fundamental, ensino médio e na educação de jovens e 